\title{
Tincture of time
}

\author{
Erin Nissen Castelloe \\ Pharmaceutical Medicine Consultant, San Diego, CA, USA
}

\begin{abstract}
In this article (part two of a two-article piece), I, Erin Nissen Castelloe, meditate on long-standing frustrations originating from my personal experiences in clinical medicine. My exit from clinical medicine can most succinctly be attributed to burnout, burnout triggered by inadequate time to address my patients' needs and complete the tasks mandated by the healthcare delivery system in which I worked. Self- and system-imposed pressures to meet my professional obligations led to chronic overwork, reduced personal time, sleep deprivation, exhaustion, and ultimately, recognition that my work situation was unsustainable. For more than ten years, I have questioned my decision to leave clinical medicine, hashing and rehashing the circumstances leading up to it. I am ready to let go of the questions that have haunted me, but I want to do so deliberately, considering them carefully before I release them. Therefore, with high hopes to understand my past, accept it, and move boldly into my future in medicine - I searched the literature, focusing on burnout in physicians and physicians-in-training; the role of time pressures in burnout; and the value of physicians spending adequate and high-quality time with patients.
\end{abstract}

\section{Introduction}

In this paper, Dr. Castelloe meditates on long-standing frustrations originating from her personal experiences in clinical medicine. ${ }^{1}$ Her exit from clinical medicine can most succinctly be attributed to burnout. ${ }^{2}$

Act at your own pace, with decisiveness. ${ }^{3}$ Time is a slippery, fickle thing: now fleeting, now interminable. Sometimes, it washes over you in waves that defy notice or quantification. Other times, a mere moment can be held

Correspondence: Erin Nissen Castelloe, 12594 Kestrel Street, San Diego, CA 92129, US

Tel.: +1.858.354.6441.

E-mail: erin@castelloe.org

Key words: Burnout, therapeutic presence, visit length, time, patient-physician relations.

Conflict of interest: Erin Nissen Castelloe works as a paid pharmaceutical medicine consultant to several drug-development companies; she does not own or accept stock (or stock options) from any drug-development company for which she works.

Acknowledgements: With humble thanks to the family, friends, and colleagues who reviewed drafts of this manuscript and the ideas therein.

Received for publication: 8 July 2017.

Accepted for publication: 8 July 2017.

This work is licensed under a Creative Commons Attribution NonCommercial 4.0 License (CC BY-NC 4.0).

CCopyright E.N. Castelloe, 2017

Licensee PAGEPress, Italy

Qualitative Research in Medicine \& Healthcare 2017; 1:103-108

doi:10.4081/qrmh.2017.6925 up to the light and minutely examined before it finally flits away. This ever-changing nature of time is inextricable from my memories of clinical medicine: expansive fortyfour-hour shifts that seemed as though they would never end, contrasting with an endless stream of brief appointments, each over-and-done before I properly felt it begin. As a primary care physician in a large, multispecialty, group practice, I had no power - despite numerous attempts to wrest it from the administration - to change my patient appointment schedule or visit length. Fifteen- or thirty-minute appointments - with mandatory doublebooking - came with the job. I could not act at my natural pace. To do so, I needed more time to listen to each of my patients; think deeply about their questions and concerns; formulate a collaborative and cohesive plan of action; document that plan, perhaps honing it as I went; and pause briefly - to reflect, breathe, recharge - before repeating the process with another patient. Instead, I worked at an unnatural, externally imposed pace, racing through and from visit to visit, day after day, week after week, month after month, year after year... until I could race no more.

I left clinical medicine exhausted and overwhelmed by feelings of inadequacy; inadequacy that devolved into slow-burning shame; shame that whispered nagging questions; questions that continue to haunt me. Why couldn't I hack it? Was I less resilient than other physicians? Did I belong in clinical medicine in the first place? If so, what more could I have done to stay? Over the years, as recognition of and concern about the prevalence of professional burnout increased, my questions evolved. Was my burnout the product of a poor fit between me - all my innate and acquired strengths and challenges - and my career choice, or simply a poor fit between me and the healthcare system in which I worked? Should I have changed practice settings before I turned away from clinical medicine? With these questions 
in mind and high hopes - to understand my past, accept it, and move decisively into my future in medicine - I reviewed the literature.

I began with broad questions. Why do physicians burn out? Do physicians recover from burnout? What aids burnout recovery? Then, I narrowed my focus toward topics relevant to my professional experiences. What is the role of time pressure in physician burnout? Would lifting time pressure prevent burnout and/or aid in burnout recovery? What are the benefits of lifting time pressure for physicians? For patients? From January to July 2017, I formally searched multiple repositories of lay and academic literature (e.g., online newspapers, news magazines, physician blog posts and/or web sites, newsletters from physician organizations, books, MEDLINE4/ PubMed, ${ }^{5}$ Google Scholar, ${ }^{6}$ a special collection published by NEJM Catalyst, ${ }^{7-10}$ Medscape $^{11}$ ) for content related to burnout (in physicians or physicians-in-training); the therapeutic nature of a physician's presence (independent of other treatment modalities); and the relationship between visit length (i.e., the amount of time that a physician spends with a patient during a discreet visit) and burnout, and/or the physician-patient relationship.

My search of the burgeoning burnout literature was extensive (Table 1), and I identified publications that generally mention the issue of time pressures in clinical medicine, listing long duty hours, chaotic work environments, lack of physician control over their schedules, and extensive administrative tasks that deprive physicians of necessary time with patients as factors impacting burnout. ${ }^{12}$ Yet, I was unable to identify a single publication that focused primarily on the role of time pressures in burnout. Initially, it seemed that my search had been fruitless; this detailed process had not revealed clear or simple answers to the questions that haunted me when I began. However, by interweaving resonant passages with my reflections on burnout, I have achieved new insights and refined my goals.

On May $6^{\text {th }}, 2017$, I conducted a PubMed ${ }^{13}$ search for the Medical Subject Heading (MeSH) of "burnout, profes- sional" and identified 5,407 English-language articles, 1,445 of which had been published in the last five years. I reviewed more than 500 of these 1,445 article titles and/or abstracts to distinguish studies which investigated physicians or physicians-in-training from those which investigated other professionals. Next, I created a list of more than fifty study factors - hypothesized to be correlated (positively or negatively) with, impacted by, causes of, and/or interventions for burnout in physicians or physicians-intraining - and sorted the list into four broad categories; the categorized study factors are presented in Table 1.

Whatever inspiration is, it's born from a continuous I don't know. (Wislawa Szymborska) ${ }^{13,14}$ Time is of the essence in healthcare; but what is the essence of time in healthcare? In a medical emergency, rapid-fire assessments and treatments by front-line providers save countless lives and limbs. To those who regard medicine as big business, ${ }^{15,16}$ both the time it takes a physician to provide a service and the complexity of that service have a relative value unit (RVU); ${ }^{17}$ meaning, the more quickly a physician can perform a procedure and the more complicated each procedure, the more valuable that physician is to the organization. Others assert that time has ethical significance, with specific implications for the patient-physician relationship, for respect of patient autonomy, for promotion of well-being... ${ }^{18}$ For me, the most precious part of my job as a family physician was the time I spent with each patient; that is where it all came together, where I found myself in flow, ${ }^{19,20}$ in harmony with the machinations of my mind and my patient.

Dr. Danielle Ofri ${ }^{21}$ states: A substantial portion of healing comes from the communication and connection with the patient...the simple conversation between doctor and patient can be as potent an analgesic as many treatments we prescribe... Yet the conversation between doctors and patients is one of the least valued aspects of medical care. Insurance reimbursements for tests and medical procedures dwarf reimbursements for talking to patients or spending time thinking about what ails them. ${ }^{22}$

Table 1. Recent research topics in physician burnout.

Physician characteristics

A sense of calling, altruism, work passion, professionalism and/or professional commitment, perfectionism, gender, resilience, wellness or well-being, emotional intelligence, genetic factors, temperament and character, achievement goal motivation orientations, self-esteem, self-efficacy.

\section{Sources of physician stress and/or burnout}

Medical culture, stigma associated with help-seeking, administrative burdens, electronic health records, environmental influences, perceived quality of care, patient safety, the physical and psychological demands of medical practice, inadequate sleep, inadequate exercise, interprofessional relations, job dissatisfaction, duty hours, workload, chronic overwork, trauma, patient characteristics, stereotypes.

Sequelae of physician stress and/or burnout

Alcohol use, emotional pain, loneliness, depression and/or depression treatments, altered brain activity on neuroimaging, suicide, medical errors, shame, blame.

Protections against and/or interventions for burnout

Mentoring, mindfulness and/or mindfulness-based stress reduction, meditation, social support, coping strategies. reflective professional supervision, computer- or phone-based applications (apps), work-life balance. 
Stanford oncologist Lidia Schapira ${ }^{23}$ expands on these ideas, writing: ...patients want to be known and respected by their professional caregivers...relationships matter... and have a healing quality, even in the face of therapeutic failure. ${ }^{24}$ The quality of communication and connection between doctor and patient are nebulous, difficult - if not impossible - to grasp, let alone measure. Yet, the Institute for Healthcare's Triple Aim Initiative - The Best Care for the Whole Population at the Lowest Cost $t^{25}$ - recognizes the importance of the patient's experience of healthcare, a key component of which is their interactions with physicians. Drs. Thomas Bodenheimer and Christine Sinsky assert that care of the patient requires care of the provider... [and] recommend that the Triple Aim be expanded to a Quadruple Aim, adding the goal of improving the work life of health care providers... ${ }^{26} \mathrm{I}$ hope that my relationships with patients were positive parts of their experience of healthcare, brought them some sense of sustenance, if not healing. I know those relationships buoyed me. They carried me through the sea of paperwork and the long hours. So, when my administration turned the screws, clamping down on the time I could spend with each patient, I began to sink. How might this have impacted my patients?

Antony Broyard, in an ethereal reflection on his experiences as a patient with prostate cancer, wished for something more in his relationship with his doctor. He wrote, I would like a doctor who is not only a talented physician but a bit of a metaphysician too, someone who can treat body and soul...I wouldn't demand a lot of my doctor's time; I just wish he would brood on my situation for perhaps five minutes, that he would give me his whole mind just once...I have a wistful desire for my relation to my doctor to be beautiful - but I don't know how this can be brought about. ${ }^{27}$ What if we not only acknowledged but embraced the therapeutic and ethical essences of time in healthcare? What if we encouraged physicians to spend the time necessary to meet the needs of each patient? What if we honored patients by giving them the time they want, need, and deserve with their doctors? Might we foster beautiful physician-patient relationships, enhance healing, and combat burnout?

Neither my burnout nor its source (i.e., inadequate time to address patient needs) are unique. A ground-breaking national survey of physicians in the United States (US) in 2011 revealed: ...the prevalence of burnout among US physicians is at an alarming level...physicians in specialties at the front line of care access (emergency medicine, general internal medicine, and family medicine) are at greatest risk... The fact that almost 1 in 2 US physicians has symptoms of burnout implies that the origins of this problem are rooted in the environment and care delivery system rather than in the personal characteristics of a few susceptible individuals. Policy makers and health care organizations must address the problem of physician burnout for the sake of physicians and their patients. ${ }^{28}$
The same team published a follow-up national survey of US physicians in 2014 - conducted in a manner comparable to that of 2011 - and concluded: Burnout and satisfaction with WLB [work-life balance] among US physicians are getting worse. American medicine appears to be at a tipping point with more than half of US physicians experiencing professional burnout... There is an urgent need for... addressing the drivers of burnout among physicians. These interventions must address contributing factors in the practice environment rather than focusing exclusively on helping physicians care for themselves and training them to be more resilient. ${ }^{29}$

Per my PubMed search (Table 1), most physician burnout research published in the last five years focused on physician factors or physician-mediated interventions, with much less research proposing modification of practice environments and/or healthcare systems to address burnout. Yes, doctors, like everyone else, are supposed to eat right, exercise regularly, and get adequate sleep. In addition, some - including the American Medical Association - assert that doctors should participate in resiliency trainings, ${ }^{30}$ mindfulness-based stress reduction (MBSR) courses, and wellness programs. Yet, if their personal and professional obligations remain unchanged, just when are they supposed to find the time to participate in these timeconsuming, health- and wellness-promoting activities?

The healthcare system status quo remains the same: physicians remain under tremendous pressure to deliver (and document) more complex care for more patients in less time, and we are indoctrinating new generations of physicians to the status quo. The 80 -hour work week is here to stay for physicians-in-training. (Beyond residency, the 80 -hour work week may be exceeded.) On March $17^{\text {th }}$, 2017, the Accreditation Council for Graduate Medical Education (ACGME) ${ }^{31}$ released a memo in which it announced that it had preserved the 80 -hour work week and the maximum frequency of in-house call (every third night), while increasing the number of consecutive hours that first-year residents (i.e., interns) can work from 16 hours to 28 hours ( 24 hours, plus up to four hours to manage necessary transitions) so that first-year residents will have the same maximum shift-length as residents beyond their first year. They acknowledge that the question of work hour standards appropriately provokes great emotion in both the graduate medical education community and among segments of the general public...recognize the significant risk of burnout and depression for physicians... [and are obligated to] help physicians find meaning and joy in their work, while also providing them with the resources necessary to care for themselves and their patients. Yet, they are assured that their decision is right because [r] esearch conducted over the past five years confirms that the cap of 80 hours worked per week (adopted by the ACGME in 2003)... provides the best balance between simulating real word experiences [for] residents ... with their ability to be properly rested. ${ }^{32-34}$ 
In the real world, physicians are burning out at an alarming rate. They are not getting what they want and need to sustain and promote their long-term professional and/or personal health and wellbeing. Heightened awareness of this crisis, and its potential impact on patient care ${ }^{35}$ has triggered numerous well-intended reactions, each designed to address hypothesized drivers of burnout. The American College of Physicians (ACP) ${ }^{36}$ has linked increasing administrative tasks to greater stress and burnout in physicians and developed the Patients Before Paperwork initiative in 2015..$^{37,38}$ The same year, the NEJM Group ${ }^{8}$ launched NEJM Catalyst, ${ }^{9,10}$ a think-tank engaged in the burnout conversation which recently released a publication entitled Physician Burnout: The Root of the Problem and the Path to Solutions ${ }^{7}$. Most medical schools and residency programs have launched wellness programs. ${ }^{39-45}$ Shouldn't I feel encouraged by these efforts? In one sense, I am deeply encouraged. The ACP and NEJM Catalyst initiatives especially inspire hope because they recognize the importance of preserving a physician's time for patient care ${ }^{18,46}$ and rekindling joy in medicine. ${ }^{7}$ Yet, the more I read about resiliency trainings or wellness program proposals for physician burnout, the less convinced I am that they will be significantly effective without matching reforms to the healthcare system that protect the time that doctors need to work with and for their patients, that precious time which kindled and rekindled my joy in medicine.

Like me, Dr. Pamela Wible ${ }^{47}$ is skeptical that wellness programs alone will save our burned-out doctors, writing:... medical organizations are racing to create wellness programs as the big new innovative solution. Well that kinda seems like forward momentum. But can a wellness committee really save our doctors? Misery in medicine is at an all-time high. I get...messages...every day from miserable doctors like this one: Today I realized that if I become a dog walker and charge 25 US dollars (\$)/hour and walk 5 dogs per day I would make my equivalent salary with a lot less hassles...I could be the most over-qualified dog walker out there with a bachelors, masters, doctorate and specialty certification...Maybe that would be more helpful to society than the assembly-line medicine I currently participate in and I would likely be happier and healthier. What do you think? Here's what I think. This doctor is well. She's got normal vital signs. She exercises and eats well... [She is doing] what well-adjusted rational doctors want to do these days. Wellness is not the antidote for misery. Happiness is. ${ }^{48}$ Can the importance of happiness - to physicians and patients alike - be overestimated? Does happiness spring forth from health, from wellness? What is the role of a physician in supporting the happiness of her patients?

Dr. Peter Aird ${ }^{49}$ eloquently jettisons the idea that physicians, by rote, champion health and wellness without any understanding of what is, to their patients, most meaningful: what makes life worth living, the proverbial well- spring from which their happiness bubbles up. He writes: I went to the woods because I wanted to live deliberately, I wanted to live deep and suck out all the marrow of life; to put to rout all that was not life and not, when I had come to die discover that I had not lived... [Henry David Thoreau] With apologies to Henry Thoreau: I went to the woods because I wanted to lower my BMI, I wanted to live a bit longer than I might otherwise have done and reduce my HbAlc; to reduce my serum cholesterol below 5.0 and not, when I had come to die, discover that I really should have switched to a low fat spread...It doesn't have the same ring to it somehow... if we are to be healthier... we... have to want to be healthier because life is worth living...[to] encourage patients to look away from health as the source of their happiness to something bigger and better - something really worth living for ... ${ }^{50}$ It is the same for physicians. We will not become more resilient, mindful, well, and resistant to burnout - no matter how many resiliency trainings, MBSR courses, or wellness programs we participate in - if we cannot build and work within a system that recognizes, respects, and protects the aspects of medicine that kindle and rekindle our joy, lift us up, and renew our commitment to medicine day after day, week after week, month after month, and year after year.

\section{Conclusions}

This is your assignment. Feel all the things. Feel the hard things. The inexplicable things, the things that make you disavow humanity's capacity for redemption. Feel all the maddening paradoxes. Feel overwhelmed, crazy. Feel uncertain. Feel angry. Feel afraid. Feel powerless. Feel frozen. And then FOCUS. Pick up your pen...Pick up your damn chin... Reveal the fierce urgency of now. Reveal how shattered we are, how capable of being repaired. But don't lament the break. Nothing new would be built if things were never broken. A wise man ${ }^{51}$ once said: There's a crack in everything. That's how the light gets in. Get after that light. This is your assignment. (Wendy MacNaughton and Courtney E. Martin) ${ }^{52}$

I think taking the time to care for patients - with empathy, deep consideration, and mutual respect - was my light. Indeed, it was the principal reason that I pursued medicine as a career; it was the assignment I gave myself. Those of us who have burned out have invaluable insights to share. We must not rely on policy makers and health care organizations to address burnout; we must contribute what we have learned and work to prevent and heal burnout - and its dire consequences ${ }^{53-55}$ - in ourselves and our colleagues. But how do we begin?

In a blog post, an anonymous physician shares: $I$ burned out, big and bad. I can see that now. My practice environment had become gradually untenable and every attempt I made to change it was blocked... Risk management shudders at burned-out doctors and strongly recommends avoidance. But we're still here, we're still trained 
physicians, and we'd like to get back on our feet. It's taken me a long time to get to a point where I can share this. It's not pretty, it's not pleasant, but it is happening more and more. Those of us who make it through burnout would like a way to rebuild. We need to start talking about what comes after physician burnout. Please. ${ }^{56}$ What will become of this anonymous doctor who wants to talk about what comes after burnout? She may not see a way forward because the path has not yet been trodden. Or, it has been traveled by so few that it is hard to find. In her words, I read loneliness, desperation, and an emphatic plea for a companionable hand to reach out and help her up and along the path. Though she may not realize it yet, she has, by sharing her story, taken her first step toward rebuilding her life. What comes next?

This hashing and rehashing of my decision to leave clinical medicine tethers me to my past and, in some ways, hinders my forward progress. Yet, I do not consider it a waste of time to examine my unlived life, the parallel life I might have led ${ }^{57}$ Rather, I consider it a natural stage in my grieving process. I grieve the loss of this dream I nurtured for decades and the relationships I might have cultivated and maintained with my patients. I had to experience some combination of denial, isolation, anger, bargaining, and depression ${ }^{58}$ before I could reach any type of acceptance, inner peace, and resolution to act, at my own pace, with decisiveness. ${ }^{3}$

Had I been able to press a pause button on my life, I might have progressed more quickly through my stages of grief. However, I chose to mend the machine while it was in motion $^{59}$, working hard to maintain a relevant presence - albeit a nonclinical presence - in medicine. According to a recent article in Harvard Business Review, ${ }^{60}$ the busier we are, the more critical it is to step away from the noise and cultivate silence. When we're constantly fixated on the... agenda...it's tough to make room for truly different perspectives or radically new ideas. It's hard to drop into deeper modes of... attention. And it's in those deeper modes of attention that truly novel ideas are found. ${ }^{61}$ Recently, I have been moved to heightened self-awareness by a number of circumstances and have cleared ground in my schedule. ${ }^{1}$ I have allowed myself the time, space, and silence to consider my past, truly different perspectives, and radically new ideas, holding them up to the light to determine their suitability for me, with all my strengths and challenges. Like me, medicine has its strengths and challenges. Burnout is a challenge that we both face. Therefore, both of us will need to gaze unflinchingly at our cracks - precious cracks through which the light gleams ${ }^{51}$ - to become truly selfaware, evolve, reform our best practices, become excellent, and achieve our full potential. This process is daunting; it will require strength, dedication, collaboration, truly novel ideas, and time, tincture of time. Yet, the journey of a thousand miles begins with one step. ${ }^{62}$ Let's begin.

\section{References}

1. Castelloe E. Finding myself in medicine. Qual Res Med Health 2017;1:1-5.

2. Maslach C, Schaufeli W, Leiter M. Job burnout. Ann Rev Psychol 2001;52:397-422.

3. Mindfulness. Newsweek Special Edition. 2017:18.

4. MEDLINE Fact Sheet Nlm.nih.gov. 2017 [cited 23 May 2017]. Available from: https://www.nlm.nih.gov/pubs/factsheets/medline.html

5. PubMed NCBI Ncbi.nlm.nih.gov. 2017 [cited 8 May 2017]. Available from: https://www.ncbi.nlm.nih.gov/pubmed/

6. Google Scholar. 2017 [cited 18 May 2017]. Available from: https://scholar.google.com/

7. Shanafelt T, Swensen S, Mohta N, et al. Physician burnout: the root of the problem and the path to solutions. Boston: NEJM Catalyst; 2017 pp 1-52.

8. NEJM Group. 2017 [cited 7 June 2017]. Available from: http://nejmgroup.org/

9. NEJM Catalyst - Home - Practical Innov Health Care Deliv NEJM Catalyst. 2017 [cited 7 June 2017]. Available from: http://catalyst.nejm.org/

10. Lee T, Campion E, Morrissey S, Drazen J. Leading the transformation of health care delivery: the launch of NEJM catalyst. N Engl J Med 2015;373:2468-9.

11. Latest Medical News, Clinical Trials, Guidelines: today on Medscape. Medscape.com. 2017 [cited 16 July 2017]. Available from: http://www.medscape.com/

12. Linzer M, Poplau S, Babbott S, et al. Worklife and Wellness in academic general internal medicine: results from a national survey. J Gen Intern Med 2016;31:1004-10.

13. Wislawa Szymborska. Nobel lecture: the poet and the world. Nobelprize.org. 2017 [cited 17 July 2017]. Available from: http://www.nobelprize.org/nobel_prizes/literature/laureates/1996/szymborska-lecture.html

14. Wisława Szymborska. Poetry Foundation 2017 [cited 16 July 2017]. Available from: https://www.poetryfoundation.org/ poets/wisaawa-szymborska

15. Gross T. How U.S. health care became big business. NPR.org. 2017 [cited 23 May 2017]. Available from: http://www. npr.org/sections/health-shots/2017/04/10/523005353/how-us-health-care-became-big-business

16. Rosenthal E. An american sickness. New York: Penguin Press; 2017.

17. RVUs: A valuable tool for aiding practice management. Med Econ 2017

18. Braddock C, Snyder L. The doctor will see you shortly. the ethical significance of time for the patient-physician relationship. J Gen Intern Med 2005.

19. Csikszentmihalyi M. Flow. New York [u.a.]: Harper\& Row; 2009.

20. Csikszentmihalyi M. Finding flow in everyday life. New York: BasicBooks; 1997.

21. Ofri D. Author and associate professor of medicine at NYU 2017 [cited 23 May 2017]. Available from: http://danielleofri.com/

22. Ofri D. The conversation placebo. Nytimes.com. 2017 [cited 30 March 2017]. Available from: https://www.nytimes.com/ 2017/01/19/opinion/sunday/the-conversation-placebo.html? smprod=nytcore-iphone\&smid=nytcore-iphone-share\&_r $=0$

23. Schapira L, FASCO Cancer.Net. 2017 [cited 7 June 2017]. Available from: http://www.cancer.net/about-us/cancerneteditorial-board/associate-editors/lidia-schapira-md-fasco

24. Schapira L. The essential elements of a therapeutic presence. 
Cancer 2013;119:160-10. Available from: http://onlinelibrary.wiley.com/doi/10.1002/cncr.27946/pdf

25. The IHI Triple Aim. Ihi.org. 2017 [cited 17 July 2017]. Available from: http://www.ihi.org/Engage/Initiatives/TripleAim/ Pages/default.aspx

26. Bodenheimer T, Sinsky C. From triple to quadruple aim: care of the patient requires care of the provider. Ann Fam Med 2014;12:573-6.

27. Broyard A. Doctor talk to me. Nytimes.com. 2017 [cited 8 May 2017]. Available from: http://www.nytimes.com/1990/ 08/26/magazine/doctor-talk-to-me.html?pagewanted=all

28. Shanafelt T, Boone S, Tan L, et al. Burnout and satisfaction with work-life balance among us physicians relative to the general US population. Archiv Intern Med 2012;172:1377.

29. Shanafelt TD, Hasan O, Dyrbye LN. Changes in burnout and satisfaction with work-life balance in physicians and the general US working population between 2011 and 2014 . Mayo Clin Proc 2015;90:1600-13.

30. Improving physician resiliency. STEPSforward.org. 2017 [cited 18 May 2017]. Available from: https://www.stepsforward.org/modules/improving-physician-resilience

31. ACGME. Acgme.org. 2017 [cited 17 July 2017]. Available from: http://www.acgme.org/

32. ACGME Common program requirements. Acgmecommon.org. 2017 [cited 17 July 2017]. Available from: https:// acgmecommon.org/announcement

33. Dwyer C. Rookie doctors will soon be allowed to work up to 28 hours straight. NPR.org. 2017 [cited 7 May 2017]. Available from: http://www.npr.org/sections/thetwoway/2017/03/10/519662434/rookie-doctors-will-soon-be-allowed-to-work-up-to-28-hours-straight

34. Asch D, Bilimoria K, Desai S. Resident duty hours and medical education policy - raising the evidence bar. N Engl J Med 2017;376:1704-6.

35. Allen M, Pierce O. Medical errors are no. 3 cause of U.S deaths, researchers say. NPR.org. 2016 [cited 18 April 2017]. Available from: http://www.npr.org/sections/healthshots/2016/05/03/476636183/death-certificates-undercounttoll-of-medical-errors

36. American College of Physicians, Internal Medicine, ACP. American College of Physicians. 2017 [cited 7 June 2017] Available from: https://www.acponline.org/

37. Erickson S, Rockwern B, Koltov M, McLean R. Putting patients first by reducing administrative tasks in health care: a position paper of the American College of Physicians. Ann Intern Med 2017 [In press].

38. American College of Physicians. Patients before paperwork. Where we stand, ACP. 2017 [cited 18 April 2017]. Available from: https://www.acponline.org/advocacy/where-we-stand/ patients-before-paperwork

39. Hobson K. New medical school programs help students battle burnout. US News World Rep 2013 [cited 9 June 2017]. Available from: https://www.usnews.com/education/bestgraduate-schools/top-medical-schools/articles/2013/03/21/ new-medical-school-programs-help-students-battle-burnout

40. Daye D. Student wellness initiatives (compiled from the American Association of Medical Colleges' Organization of Student Representatives). American Association of Medical Colleges (AAMC). 2013 [cited 9 June 2017]. Available from: https://www.aamc.org/download/351946/data/studentwellness.pdf

41. Noori S, Blood A, Meleca J, et al. Current directions in medical student wellbeing: a primer for students. American Association of Medical Colleges / Organization of Student
Representatives. 2017 [cited 9 June 2017]. Available from: https://www.aamc.org/download/450164/data/medstudentwellbeing.pdf

42. Vassar L. How one program achieved resident wellness, work-life balance. AMA Wire 2015 [cited 9 June 2017]. Available from: https://wire.ama-assn.org/life-career/howone-program-achieved-resident-wellness-work-life-balance

43. Okanlawon T. Physician wellness: preventing resident and fellow burnout. STEPSforward.org 2017 [cited 9 June 2017]. Available from: https://www.stepsforward.org/modules/physician-wellness

44. Eckleberry-Hunt J, Van Dyke A, Lick D, Tucciarone J. Changing the conversation from burnout to wellness: physician well-being in residency training programs. J Grad Med Educ 2009; 1:225-230.

45. Kiersz B. Promoting wellness in a family medicine residency program. Society of Teachers of Family Medicine (STFM). 2016 [cited 9 June 2017]. Available from: http:// www.stfm.org/NewsJournals/EducationColumns/September2016EducationColumn

46. Tai-Seale M, McGuire T, Zhang W. Time allocation in primary care office visits. Health Serv Res 2007;42:1871-94.

47. Wible P. Ideal medical care. Idealmedicalcare.org 2017 [cited 17 July 2017]. Available from: http://www.idealmedicalcare.org/

48. Wible P. The weird reason why wellness programs won't work. Available from: http://www.idealmedicalcare.org/ blog/weird-reason-wellness-programs-wont-work/

49. Aird P, The BJGP blog. Bjgpblog.com. 2017 [cited 17 July 2017]. Available from: https://bjgpblog.com/tag/peter-aird/

50. Aird P. Health: it'll be the death of us: institutional arrogance in the health service? Br J Gen Pract 2012;62:317-8.

51. The official Leonard Cohen site. Leonardcohen.com 2017 [cited 17 July 2017]. Available from: http://www.leonardcohen.com/

52. A responsibility to light: an illustrated manifesto for creative resilience and the artist's duty in dark times. Brain pickings 2017. Available from: https:/www.brainpickings.org/ 2017/05/15/focus-wendy-macnaughton-courtney-martinposter/

53. Kuhn C, Flanagan E. Self-care as a professional imperative: physician burnout, depression, and suicide. Canad J Anesthesia/J Canad Anesth 2016;64:158-68.

54. Muller DK. N Engl J Med 2017;376:1101-3.

55. Hill A. Breaking the stigma: a physician's perspective on self-care and recovery. N Engl J Med 2017;376:1103-5.

56. We need to start talking about what comes after physician burnout. KevinMD.com. 2017 [cited 16 July 2017]. Available from: http://www.kevinmd.com/blog/2017/02/needstart-talking-comes-physician-burnout.html

57. Phillips A. Missing out. New York: Farrar, Staus and Giroux; 2012.

58. Kubler-Ross E, Byock I. On death \& dying.

59. Tolstoy L. Anna Karenina, 1877.

60. Ideas and advice for leaders. Hbr.org. 2017 [cited 17 July 2017]. Harvard Business Rev. Available from: https://hbr.org/

61 . The busier you are, the more you need quiet time. Harvard Business Rev 2017 [cited 16 July 2017]. Available from: https://hbr.org/2017/03/the-busier-you-are-the-more-youneed-quiet-time

62. BBC World Service. Learning English. Moving words. Bbc.co.uk. 2017 [cited 17 July 2017]. Available from: http://www.bbc.co.uk/worldservice/learningenglish/movingwords/shortlist/laotzu.shtml 